\title{
In-house production versus specific forms of supplier governance: testing predictions of the global value chains model
}

\section{Alexander Schmitt}

University of Leuven (KU Leuven), Naamsestraat 69, 3000 Leuven, Belgium

Email: alexander.schmitt@kuleuven.be

\section{Johannes Van Biesebroeck*}

Department of Economics,

University of Leuven (KU Leuven),

Naamsestraat 69, 3000 Leuven, Belgium

Email: Jo.VanBiesebroeck@kuleuven.be

*Corresponding author

\begin{abstract}
Carmakers interact in their supply chain with virtually all manufacturing industries. Using a novel dataset on sourcing transactions that contains links between buyers and suppliers for sourcing contracts of individual components, we show that multiple forms of relationship governance can coexist within a single industry. We first show that three characteristics of transactions that have been used to rationalise observed sourcing patterns in the global value chains (GVC) literature - complexity, codifiability and supplier capability - also predict whether components are outsourced or not. More importantly, the same characteristics help explain how carmakers choose to structure supply relationships differently depending on the situation.
\end{abstract}

Keywords: global value chains; GVC; outsourcing; supply relationships.

Reference to this paper should be made as follows: Schmitt, A. and Van Biesebroeck, J. (xxxx) 'In-house production versus specific forms of supplier governance: testing predictions of the global value chains model', Int. J. Automotive Technology and Management, Vol. X, No. Y, pp.xxx-xxx.

Biographical notes: 
This paper is a revised and expanded version of a paper entitled [title] presented at [name, location and date of conference].

\section{Introduction}

A large literature has emerged which studies the interactions of firms in global value chains (GVCs). The term is used to emphasise that the range of tasks and activities required to produce a good are increasingly performed by independent firms that are located in different countries. Calling this a value chain rather than a supply chain further emphasises that this phenomenon goes beyond the sequential production steps, but encompasses all activities that add value to a product, including design, logistics, and marketing.

The GVC literature is replete with empirical evidence supporting the view that buyersupplier relationships are not all of a same, generic kind. Many case studies illustrate that the way relationships are governed depends on the norms and standards of an industry, the technological maturity of the components being traded, and the distribution of power. However, most studies look at either a specific industry or a handful of special cases, which makes it difficult to disentangle the unique features of relationship governance in an industry from the underlying forces that determine the choices of firms more generally, e.g., choices of scale and technology.

We follow the GVC literature, in particular the stylised model of Gereffi et al. (2005) to obtain predictions about the optimal form of governance in different situations. In that model, three key characteristics of transactions - i.e., complexity, codifiability and the capabilities of the supply base - are used to identify five situations that call for different forms of relationship governance. They are labelled hierarchical, captive, relational, modular and market. While these labels do not have much meaning on their own, the wealth of case studies conducted by GVC researches provides information on features that characterise each particular governance form, even when it occurs in different industries. ${ }^{1}$

The objective of this paper is to verify whether the GVC predictions are confirmed in the sourcing patterns of automakers. We exploit the well-documented fact that the automobile sector is one of the most downstream manufacturing industries see for example Antràs et al. (2012). It implies that carmakers need to interact with virtually all other manufacturing industries and will source inputs in a wide range of situations. As cars are very complex products consisting of a bewildering number of components, the automotive industry is a unique laboratory to test the GVC theory in a systematic way. It touches on a myriad of other industries, generating different situations for the same set of lead firms. We can thus verify whether they tailor their behaviour, i.e., their supplier governance, to the situation. We ask whether the same firm organises separate parts of its supply chain differently if the situation calls for it. We will analyse quantitatively whether the correlation between governance types and the characteristics of the product or supplier accords with the GVC predictions. 
In our empirical analysis we use a rich new data set of supply relationships between carmakers and automotive suppliers for individual components, see Schmitt and Van Biesebroeck (2013) for details. A transaction is defined as a buyer-supplier-component triplet and we observe more than 50,000 of them. We use this information to make two contributions. First, we show how we can operationalise the GVC theory by constructing proxies for each form of relationship governance form in a generic way, while measuring the three characteristics of transactions in a way tailored particularly to the automotive sector. Second, as we are careful to use independent information to measure both sets of variables, we test whether the GVC predictions linking the characteristics to optimal governance types are borne out in the data. We start by focusing on the initial outsourcing decision, but show how sourcing evolves once it is initiated.

We find that the predictions of the GVC theory hold to a large extent. To understand why multiple forms of relationship governance can coexist within a single industry, we propose the following logic. It is easiest to describe it in a dynamic way, suggesting an evolution over time, but it applies similarly to compare transactions with different characteristics at one point in time. When new components using novel technologies are introduced, they tend to be complex. No suppliers exist that have the knowledge or capabilities to produce them and a lack of standardisation makes it hard to codify design and performance requirements (Stigler, 1951). Hence, carmakers will initially prefer to produce them in-house. As technologies evolve and production and design practices are perfected, some of the initial difficulties associated with outsourcing can be overcome. If codifiability improves first, it allows for a switch from hierarchy (in-house production) to captive governance; if the capability of existing suppliers improves first, relational governance will be the first choice of governance form. Subsequently, as suppliers gain experience they will further improve their capabilities and find out ways to codify aspects of the transaction, allowing the superior modular form of governance to become viable (Sturgeon, 2002). It allows carmakers and suppliers to focus on their respective comparative advantages, while still stimulating technological innovation. With this shift, the balance of power also tends to shift from the buyer to the supplier. Finally, when an existing technology becomes common knowledge and best practices become widespread, lower transaction complexity allows the market form of governance to emerge, where competition is more on price than on quality.

Our objective is not to derive implications for strategy and policy or generate predictions about the future, but to assess the explanatory power of one specific theoretical model. Our findings build on the GVC literature and provide supporting evidence exploiting the interactions of a narrow set of automotive lead firms with a broad range of other manufacturing sectors. Bensaou (1999) uses a different conceptual framework, but exploits this same feature of the auto industry. The approach differs from many other studies that provide evidence for the popularity of one governance type in one particular sector or investigate which governance type is the best characterisation for observed relationships in one sector, e.g., Asanuma (1989), Humphrey (2003) and Sturgeon et al. (2008) do this for the automotive sector. By focusing on the predictive power of a few key characteristics, we illustrate the predictive power of GVC theory and along the way we discuss to what extent these predictions differ from those made in the field of transaction cost economics (Klein et al., 1978; Williamson, 1979) or the property rights theory, (Grossman and Hart, 1986) which have been particularly influential in the theory of the firm. 
The remainder of the paper is organised as follows. In Section 2 we give some background information on the breath of sourcing relationships in the automotive sector. In Section 3 we describe the GVC framework and distil theoretical predictions. In Section 4 we introduce the data and measurement of the governance types and transaction characteristics. In Section 5 we present the results and we close with conclusions in Section 6 .

\section{Component sourcing in the automotive sector}

The organisation of the automotive sector, where carmakers are responsible for design, final assembly and marketing while a tiered supply chain takes up the production of thousands of different components, has been documented extensively [see for example Helper (1991) for a historical perspective]. Sturgeon et al. (2008) provide a complementary introduction, highlighting the importance of regional networks and clusters and documenting recent trends. ${ }^{2}$

We mentioned already that the auto sector interacts with many other sectors of the economy. As this feature motivates our empirical strategy to systematically test GVC predictions in a cross-section of industries, we provide concrete evidence in Table 1 which lists the most important industries where the suppliers in our dataset come from. Parts are sourced from virtually every other manufacturing industry and even many service industries provide inputs, ranging from logistics to software development. To classify transactions, we only use the two-digit NACE code for the suppliers' plants which are labelled as production locations to avoid including the activities of other divisions of a firm that might not be related to its automotive supply activities. ${ }^{3}$

Not surprisingly, sector 29, which contains firms directly working in the motor vehicle industry, occurs most frequently, but it represents fewer than $40 \%$ of observations. Sector 29 comprises several more detailed subsectors for industries such as 'manufacture of bodies for motor vehicles' (Sector 29.20) or 'manufacture of electrical and electronic equipment for motor vehicles' (Sector 29.31). Because these are industries that differ in their location along the value chain and in the dominant technology they use, sourcing practices are unlikely to be the same for all of them.

Most other manufacturing sectors are represented in Table 1. Note that even a share of just $1 \%$ in the sample represents almost 400 observations. Some service sectors, such as 'computer programming, consultancy and related activities' or 'repair and installation of machinery and equipment' are well represented too.

Given the wide spectrum of industries that suppliers come from, it is to be expected that the way they interact with automotive lead firms will also differ. A couple of important dimensions of heterogeneity are as follows: the level of sophistication of the production technology, the extent to which a particular component is integrated in a larger module, the capabilities and assets a supplier has acquired over its existence, and the importance of a component relative to the overall value of a vehicle. Each of these aspects is likely to influence the preferred form of supplier governance for lead firms. In the next section we describe the GVC theory which focuses on three characteristics in particular as determinants of sourcing relationships. 
Table 1 NACE sectors of the manufacturing plants of suppliers

\begin{tabular}{|c|c|c|c|}
\hline $\begin{array}{l}\text { two-digit } \\
\text { code }\end{array}$ & Sector description (NACE rev. 2) & $\begin{array}{l}\text { Number of } \\
\text { transactions }\end{array}$ & $\begin{array}{l}\text { Fraction of } \\
\text { total }\end{array}$ \\
\hline 29 & $\begin{array}{l}\text { Manufacture of motor vehicles, trailers and } \\
\text { semi-trailers }\end{array}$ & 14,489 & $39.2 \%$ \\
\hline 22 & Manufacture of rubber and plastic products & 4,046 & $10.9 \%$ \\
\hline 28 & Manufacture of machinery and equipment & 3,710 & $10.0 \%$ \\
\hline 25 & $\begin{array}{l}\text { Manufacture of fabricated metal products, except } \\
\text { machinery and equipment }\end{array}$ & 2,901 & $7.8 \%$ \\
\hline 20 & Manufacture of chemicals and chemical products & 2,741 & $7.4 \%$ \\
\hline 27 & Manufacture of electrical equipment & 2,165 & $5.9 \%$ \\
\hline 26 & $\begin{array}{l}\text { Manufacture of computer, electronic and optical } \\
\text { products }\end{array}$ & 1,652 & $4.5 \%$ \\
\hline 45 & $\begin{array}{l}\text { Wholesale and retail trade and repair of motor } \\
\text { vehicles and motorcycles }\end{array}$ & 1,381 & $3.7 \%$ \\
\hline 23 & Manufacture of other non-metallic mineral products & 992 & $2.7 \%$ \\
\hline 13 & Manufacture of textiles & 973 & $2.6 \%$ \\
\hline 24 & Manufacture of basic metals & 497 & $1.3 \%$ \\
\hline 32 & Other manufacturing & 410 & $1.1 \%$ \\
\hline 62 & $\begin{array}{l}\text { Computer programming, consultancy and related } \\
\text { activities }\end{array}$ & 314 & $0.8 \%$ \\
\hline 43 & Specialised construction activities & 188 & $0.5 \%$ \\
\hline 31 & Manufacture of furniture & 152 & $0.4 \%$ \\
\hline 19 & $\begin{array}{l}\text { Manufacture of coke and refined petroleum } \\
\text { products }\end{array}$ & 107 & $0.3 \%$ \\
\hline 33 & Repair and installation of machinery and equipment & 103 & $0.3 \%$ \\
\hline 30 & Manufacture of other transport equipment & 97 & $0.3 \%$ \\
\hline 17 & Manufacture of paper and paper products & 57 & $0.2 \%$ \\
\hline 15 & Manufacture of leather and related products & 16 & $<0.1 \%$ \\
\hline
\end{tabular}

Notes: This sample only includes the transactions for which we could link the supplier in our main dataset from SupplierBusiness to the Amadeus dataset from which we derived the control variables in the analysis. It amounts to $64.5 \%$ of the total sample, or 36,991 observations in total.

\section{Theoretical framework}

The GVC framework that we take as basis for our empirical analysis was introduced by Gereffi et al. (2005). Extrapolating from case studies of several industries and drawing on key variables from various theories, they argue that three variables - different characteristics of transactions or suppliers - are of crucial importance in shaping the nature of the supply relationships. As Hierarchy (in-house production) is included as one of the five possible supply relationships, the explanatory variables also influence whether outsourcing is possible or desirable at all. 
The theories and concepts the GVC theory draws upon are very extensive. It includes asset specificity from transactions cost economics, relational linkages from network theory in the fields of industrial sociology and economic geography, supplier competence and the resource view of the firm from management, and the concept of modularity from the technology management literature. As it would take us too far to revisit all these connections with the literature, we refer readers interested in the theoretical grounding of the GVC predictions to the original article. Here, we first discuss the three characteristics used to predict sourcing decisions, followed by a discussion of the five different supplier governance types and the specific predictions linking the characteristics to the governance types. We provide references along the way to connect these concepts to other literatures that readers might be already familiar with.

A first characteristic that is used widely also in other literatures is complexity. It is related to the inability to specify a supplier's obligations ex ante in an enforceable contract, the common assumption in the incomplete contracts literature. Work in transaction cost economics (TCE), see for example Klein et al. (1978) or Williamson (1979), also takes as starting point that transactions are sufficiently complex that the potential hold-up problem when they need to be adjusted in the future cannot be resolved by writing a detailed contract. This can be due to excessive uncertainty, contracting being too expensive, or contracts being unenforceable by outside parties, for example because only insiders can assess product or service quality. ${ }^{4}$

A useful, but narrow definition of codifiability, the second characteristic, is given by Levi et al. (2003). They define it as an indicator of how precise the nature of the product or service that is the subject of a contract can be characterised in electronic format. The ability to specify performance requirements ex-ante and in a readily verifiable way is one aspect that makes a transaction more codifiable. But it also includes: "delivery requirements and any other requirements that may pertain to a specific transaction, in a manner understandable to relevant parties. Codifiability has two dimensions: (1) the codifiability of the component as such and (2) the codifiability of its interfaces with other parts of the car." (Levi et al., 2003) For some products, for example a PC, all components in the system are highly codifiable and the product can be split into modules in various ways. In other cases, only specific points in the system are codifiable, for example the link between chip design and fabrication in the semi-conductor industry. The study of the electronics industry in Sturgeon (2002) highlights the important role played by codifiability in the emergence of modular, or 'turnkey' suppliers.

The third characteristic is the capability of potential suppliers. The relevance of this concept for outsourcing finds antecedents in the economics and management strategy literatures. Stigler (1951) famously wrote that outsourcing is limited by the extent of the market. Only when there are enough reliable and able suppliers around will outsourcing become a viable business strategy. Penrose (1959) launched the resource-based view of the firm. The competitive advantage of a firm, and hence also its attractiveness as a supplier, stems from the strategic resources a firm has control over and which are rare, difficult to duplicate, and valuable.

If either of the three characteristics can be high or low, they allow for a total of eight permutations or possible governance types. However, not all combinations of highs and/or lows are equally likely. In particular, for transactions or products that are not complex, it is unlikely that its performance characteristics are difficult to codify or that there exist no capable suppliers to produce it. Such situations are likely to be rare and the theory abstracts from them. If complexity is low, the codifiability and capability 
requirements for successful outsourcing will generally be met automatically. ${ }^{5}$ These requirements are not absolute, but should be assessed relative to the complexity of the transaction. As a result, we can simplify the set of possible permutations to five relevant governance types which are listed in Table 2.

Table 2 Determinants of GVC governance

\begin{tabular}{lccc}
\hline & $\begin{array}{c}\text { Complexity of } \\
\text { transaction }\end{array}$ & $\begin{array}{c}\text { Ability to codify } \\
\text { transactions }\end{array}$ & Capability of supplier \\
\hline Market & Low & High* & High* \\
Modular & High & High & High \\
Relational & High & Low & High \\
Captive & High & High & Low \\
Hierarchy & High & Low & Low \\
\hline
\end{tabular}

Notes: Adapted from Gereffi et al. (2005, p.87). *High codifiability and high supplier capability for market governance has to be interpreted in light of the low complexity of the transaction. They are not necessarily higher than the low values that are indicated for either dimension further below in the table in the case of complex transactions.

At the two extremes, in the first and last lines, are the make-or-buy options that also feature in standard economic models on the theory of the firm. If a transaction is not complex, outsourcing is feasible and suppliers will mainly compete on price. In the GVC framework, such relationships are called market, as buyers and sellers have minimal interactions and can even be anonymous. This fits well with many models that focus on market clearing and the role of demand and supply shifters. It contrasts with the situation depicted in the bottom line of Table 2 where transactions are complex, but it is difficult or impossible to codify performance characteristics and there are no suppliers with the necessary capabilities to produce the parts. In that case, the only viable alternative for the buyer is to make the part in-house, called hierarchy. Gibbons (2005) presents several distinct modelling approaches to study this make-or-buy, markets-versus-hierarchy, and dichotomy in a unified framework

The novel aspect of the GVC framework is to consider the intermediate governance types where products are outsourced, but not left to impersonal markets where price is the dominant product dimension. In a modular relationship, the supplier will have unique technology or capabilities that can be generically applied in products sold to several clients. The modular supplier will perform several activities, with break-points in the value chain occurring where the information exchange regarding a product's performance or functionality can be formalised easily. The relational-type of supplier governance will feature intensive collaboration between the client and supplier, characterised by frequent meetings to exchange information and solve problems together. Often, personnel of one of the firms will work on the other firm's premises. The defining characteristic in a captive relationship is the high concentration of a supplier's sales with a single client. Often, the client discourages a supplier to work for its competitors.

Others have of course also made contributions in this direction. The seminal work of Powell (1990) highlights the important category of network interactions where the buyer-supplier relationship is much more involved than in market interactions. Baker et al. (2002) study relational contracts which can be readily applied to the buyer-supplier 
interaction. Their repeated interaction framework is very flexible, but as we know from the 'folk theorem' in game theory it can rationalise virtually every type of interaction. Williamson (1985) analyses a variety of dedicated forms of organisation or contracting that can suit the needs of a situation. Levin and Tadelis (2010) provide an explicit model with empirical evidence studying alternative contracting forms used in government procurement. Helper (1991) shows how relationships in US automotive industry have evolved from the traditional arm's length market type.

The attractiveness of the GVC framework is that it limits the intermediate governance forms to only three 'types' and that only two characteristics are used to distinguish between different complex transactions. The theory thus generates explicit and testable predictions. For each of the governance forms in the five rows of Table 2 we are given a combination of high or low values of the characteristics that would make that particular form the most preferred one. In our empirical analysis, we will test the GVC theory by verifying whether differences in characteristics indeed correspond to the predicted differences in the observed governance.

Naturally, other characteristics of transactions besides those in the three columns of Table 2 are important and they could be introduced to obtain a finer typology of souring types. Specifically for the auto sector, important aspects that are omitted are the technology transfer to local firms happening through the collaboration with MNCs (Sönmez, 2013) and the enduring importance of distance in the selection of suppliers (Schmitt and Van Biesebroeck, 2013). ${ }^{6}$ However, the three types listed are useful because a wealth of case study evidence exists that describes various aspects of these sourcing types and makes the differences concrete. In the next section, we will draw on the GVC literature to devise a method to identify the types in our dataset, using objective and quantifiable measures. Here, we briefly describe a few key distinctions between the three intermediate types.

When a product's performance characteristics can be straightforwardly codified, outsourcing is in principle feasible. How to organise the relationship in practice depends on the capabilities of potential suppliers relative to the complexity of the product. When the product is not complex, almost by definition suppliers with sufficient skills can be found and we expect market transactions that are governed by price. When capabilities of suppliers are not sufficiently developed relative to the complexity of the product, one solution is for the buyer to transfer some capabilities or know-how to the supplier. It seems natural, however, that as a precondition a buyer will not allow the supplier to use the capabilities acquired in this way to work for other firms, which are often the buyer's competitors. ${ }^{7}$ Such collaborations are classified as captive outsourcing.

If product complexity and codifiability is high, but supplier capabilities have developed sufficiently such that the supplier can produce components of the required quality independently, outsourcing will be even more feasible. In this case, the supplier's bargaining power will be higher and we expect them to work for several buyers. ${ }^{8}$ Especially in sectors where technologies improve continuously over time, a supplier with capabilities that are sufficiently high to produce complex products will most likely have a comparative advantage over the buyer in certain domains. Making the part in-house becomes a less attractive solution for the buyer. This governance type, where the buyer relies heavily on a supplier and the supplier invests continually in new technologies to make its capabilities match the complexity of the product, is called a modular relationship as the supplier has a lot of control over the modules it supplies. 
The final cases are transactions which are not codifiable. If no capable suppliers exist, the buyer has no alternative but to make the part itself. But even if capable suppliers exist, outsourcing is not straightforward. It can only succeed if the two parties collaborate closely, as when the personnel of each firm works at the premises of its counterparty, or the design team of a supplier interacts regularly with that of the buyer or with other suppliers involved in the development or production of the same module, as frequent modifications are expected. This type of governance is called relational, since the buyer cannot simply hand over a purchase order and a supplier cannot produce a finished product independently. Instead, both firms need to collaborate intensely which is impossible without forming an actual relationship (Asanuma, 1989).

\section{Data and measurement}

\subsection{Dataset}

In the empirical work we use transaction-level data on first and lower-tier supply contracts. The data comes from SupplierBusiness, a consulting firm to the automotive industry, and it covers transactions from models that entered production between 1993 and 2012. It includes all major carmakers and global first-tier suppliers. In addition, the data includes over a thousand small and medium size supplier firms located in Europe and North America. In total, we observe 64 unique buyers, defined as an original equipment manufacturer (OEM) in one of the two regions, Europe or North America. We further observe 2,205 unique suppliers, defined as the product division of a supplier firm in one of the two major geographic regions. Finally, contracts are observed for 213 unique products, defined using the detailed (nested) component categories defined by SupplierBusiness. A unit of observation in our analysis is a transaction, which is defined as a unique combination of a buyer, a supplier, and a product.

To construct the dependent variables in the analysis, we use market shares defined along various dimensions, e.g., by supplier, by buyer, by product. A transaction's contribution to a market share is calculated by multiplying the projected monthly production volume of the model by the expected time of the contract. ${ }^{9}$

To construct control variables, we added firm-level data on OEMs and suppliers from Amadeus, a database with broad European coverage of firms in all sectors. The Amadeus dataset and matching process to the contracting data is described in more detail in Schmitt and Van Biesebroeck (2013). The control variables are included in the empirical analysis, but not reported in the tables with estimation results as they are not of independent interest.

Geographic proximity is known to play an important part in both the decision to outsource and the choice of outsourcing relationship (Schmitt and Van Biesebroeck, 2013). For instance, the decision to vertically integrate production sites is found to depend on proximity to input suppliers (Joskow, 1985). We therefore include the distance from the supplier plant to the client, and from the supplier plant to its nearer administrative office. In addition, we include a dummy variable for the effect of country borders, which is an important variable in the analysis of foreign direct investment. Cultural, historic, institutional and family ties are expected to play a role in the organisation of outsourcing relationships. We include a variable of cultural distance measured at the country level using survey data of Hofstede (1980). The index is 
calculated as the Mahalanobis distance over four dimensions: individualism, power distance, uncertainty avoidance, and masculinity.

We include contract length as proxied by the number of months between the start and end of production of a car model. Longer contracts can be seen as a compensation for uncertainty in a buyer-supplier relation (Joskow, 1985). We control for several aspects of the production technology of the supplier, such as the number of workers at all production plants of a supplier, the capital intensity, measured as the total value of assets per worker at the plant, and a proxy for value added, defined as operating revenues over total assets.

Finally, because differences in corporate strategies might have an important effect on governance choices, we include two sets of dummies for the region of the supplier and carmaker, as well as firm-fixed effects at the headquarters level of the carmaker.

\subsection{Three transaction characteristics}

To test the GVC predictions on the likely form of supplier governance, we construct proxies for the three characteristics listed in the columns of Table 2: codifiability, complexity, and capability. Importantly, we use information on the nature of the component or the identity of the supplier, but not information related to the buyer or the buyer-supplier interaction. This mirrors the approach in the seminal study of Monteverde and Teece (1982) which used expert surveys to independently assess the engineering requirements involved in the design and production of different car components as a predictor of automakers' outsourcing decision.

\subsubsection{Complexity}

To ascertain whether a part is complex or not, we exploit the tree-like structure of the component category classification as it is organised by the data provider, SupplierBusiness. We measure the complexity of each component by the number of subcategories it branches into. Our objective is not so much to capture the technological complexity of production, but the extent and intensity of interactions with the buyer or with other suppliers that work on related components. If such linkages are very deep, suppliers would be more uncertain about possible future modifications and the potential for hold-up is greater. ${ }^{10}$ In the TCE framework of Williamson (1985), greater complexity defined this way would make it less likely that a firm outsources a part.

To obtain a simple measure, we count the number of sub-categories. ${ }^{11}$ To remain close to the theory where transactions are ranked high or low on each dimension, we dichotomise the variable by indicating whether a value is below or above the sample median. In panel (a) of Table 3 we show the mean and standard deviation of all three explanatory variables. Following our procedure, the mean for the discrete complexity variable is 0.581 , which implies that $58 \%$ of the transactions in the data correspond to complex outsourcing relationships. ${ }^{12}$

\subsubsection{Codifiability}

In practice, a component is codifiable if the buyer is able to easily specify the performance characteristics the part has to meet for the supplier that will then produce and possibly also design it. If a part occurs in a large number of sub-assemblies that occur 
all over a vehicle, it is not very specific to a single module or application. Such widespread use of a component will make it appear in a larger number of outsourcing relationships and likely to be more standardised.

Table 3 Summary statistics

a Summary statistics

Mean Std. dev.

Explanatory variables

$\begin{array}{lll}\text { Complexity } & 0.581 & 0.493 \\ \text { Codifiability } & 0.307 & 0.461 \\ \text { Capability } & 0.453 & 0.498\end{array}$

Dependent variables

Hierarchy

10.98

Captive

Relational

Modular

Market
2.75

1.29
1.23

1.94

1.68

1.43

1.62 $-\ln \left(\sigma_{b s p m}\right)$

$-\ln \left(\sigma_{s} / \sigma_{b}\right)$

$-\ln \left(\sigma_{b s p} / \sigma_{s}\right)$

$-\ln \left(\sigma_{b s} / \sigma_{s}\right)$

$-\ln \left(\sigma_{s} / \sigma_{p}\right)$

$b$ Partial correlation statistics between the three explanatory variables

\begin{tabular}{lccc}
\hline & Complexity & Codifiability & Capability \\
\hline Complexity & 1 & -0.728 & 0.021 \\
Codifiability & & 1 & -0.025 \\
Capability & & & 1 \\
\hline
\end{tabular}

We again rely on the way the automotive experts of SupplierBusiness have organised the component information in the dataset. They first classified all transactions into a number of areas of the vehicle, such as engine, body and trim, interior, chassis, etc. For each of these areas there is a second level of sub-categories according to the function of the module, such as a bumper, braking system, console, etc. Below this, in the third level sub-categories, components that do not share many characteristics with others are listed in a number of unique categories. The more complex a module is, the more groups there are at this third level. Some components with standardised characteristics are produced by several firms and used in several places in the vehicle, examples include bearings, gaskets, sensors, etc. Hence, a simple measure of codifiability is a simple count of the number of times a component occurs in distinct third-level sub-categories. To make the variable less sensitive to outliers and facilitate interpretation in the regressions, we again dichotomise it by splitting it at the median.

Also for codifiability we have experimented with an alternative measure using information from outside our dataset. We alternatively classified a component as codifiable if it is covered by automotive open system architecture (AUTOSAR). ${ }^{13}$ This is a project of car assemblers and suppliers who cooperate to develop open industry standards. The initiative addresses the quickly increasing sophistication of electric and electronic systems in cars which limits the exchange of applications between assemblers and suppliers. The objective is to move away from proprietary solutions, prevalent in the car industry, and to optimise the interfaces of and interactions between components. 
Using this variable yielded consistent results, but it reduced our sample size as it is not observed for each component.

\subsubsection{Capability}

The third explanatory variable of interest is supplier capability. Following the literature on dynamic market equilibria, we measure it as the size of a supplier relative to its age. Firm dynamics in that literature stem from firms' differences in innate productivity which they discover through their own market operations. More productive firms will hire additional input factors and survive for a longer period. This selection mechanism is especially appropriate for the last 20 years in the automotive industry, as it has consolidated through mergers, witnessed a lot of supplier exit in the great recession, and the industry globalised enormously which allowed the most efficient firms to increase in size.

Haltiwanger et al. (2013) show that it is important to control for firm age when studying firm growth as it will take firms some time to reach their desired size. A related literature on firm capability and learning argues that firms compete on the basis of internal resources that take time to develop (Penrose, 1959). These capabilities do not necessarily have to be technological sophistication, but can be any skill that helps a firm to prosper and survive, e.g., low cost manufacturing prowess.

We measure size using turnover (operating revenues in 2007) and divided by the age of its main EU branch or regional headquarters. Both variables are available in the Amadeus dataset. We preferred using firm size by sales rather than R\&D expenditures as the latter variable would also capture the complexity of the components a firm produces. We again make the variable binary by assigning a value of one to all firms older than the sample median, which classifies $45 \%$ of suppliers as highly capable.

Panel (b) in Table 3 shows partial correlations between the three explanatory variables. Perhaps not surprisingly, the correlation is relatively high (in absolute value) for complexity and codifiability which were both measured based on the component classification. In contrast, the capability measure is almost orthogonal to the other two variables showing partial correlations statistics close to zero.

\subsection{Five governance types}

To identify governance types in supplier sourcing, we exploit the frequency that different transactions occur in the dataset. We could simply count transactions, e.g., calculate the share of transactions for each supplier in the dataset, in which case the variables would have a probability interpretation. However, the predictive power of the regressions proved to be higher if we weigh each transaction with the total production volume of the model it involves $\left(q_{b s p m}\right)$.

As the governance types cannot be observed directly, we rely on documented characteristics of each type from case studies in the GVC literature to construct a separate variable for each type. In particular, we construct a variable that is monotonically increasing in the likelihood a transaction is of a given type. As we want an approach that works generically, we propose a ratio of two shares as proxy for each governance type, where the literature has guided us in the selection of the different shares in the numerator or denominator. 
The first problem we faced is how to identify Hierarchy transactions. By construction, we only observe transactions for components that are actually outsourced. Transactions we do not observe could simply be missing (as the dataset is not exhaustive), they could be for specialised components not used in a particular vehicle, or they could be components produced in-house by the OEM. Our solution is to calculate the (weighted) frequency a component is outsourced as a proxy for one minus the probability of Hierarchy. If a component is rarely observed in the dataset for any of the car models, it is likely to be produced in-house by most firms (Stigler, 1951). This relies on the convergence in sourcing practices in the industry (Monteverde and Teece, 1982; Van Biesebroeck, 2003) and on a random selection of transactions into our dataset.

We normalise the frequency of outsourcing, i.e., the quantity $q_{b s p m}$ of a transaction for a given buyer, supplier, component and car model, by the total market size for parts in a year (number of vehicles produced times average number of parts per vehicle). This ratio is very small on average, but varies considerably. To use this relative market share as a measure of Hierarchy in the regressions, we take the logarithm which has much smaller variation and the mean is better centred. We also use the negative of the logarithm as it is a low value that raises the likelihood of hierarchy. ${ }^{14}$ Table 3 shows the mean and standard deviations of all dependent variables and Table 4 summarises the definition, the intuition, and the exact construction. Note that the normalisation by the total market size becomes a constant, additive term after taking logarithms and we can drop it as it does not influence the estimates.

Table 4 Definitions of the dependent variables identifying governance forms

\begin{tabular}{|c|c|c|c|}
\hline Name & Interpretation & Definition & Formula \\
\hline Hierarchy & $\begin{array}{l}\text { The transaction, which is defined at the } \\
\text { buyer-supplier-product-car model level, } \\
\text { exhibits a low market share in the } \\
\text { sample. }\end{array}$ & $-\ln \sigma_{b s p m}$ & $-\ln q_{b s p m}$ \\
\hline Captive & $\begin{array}{l}\text { Supplier } s \text { has a low market share while } \\
\text { buyer } b \text { has a high market share. }\end{array}$ & $-\ln \frac{\sigma_{s}}{\sigma_{b}}$ & \\
\hline Relational & $\begin{array}{l}\text { The specific buyer-product relationship } \\
b p \text { accounts only for a small fraction of } \\
\text { the total market share of supplier } s \text {. }\end{array}$ & $-\ln \frac{\sigma_{b s p}}{\sigma_{s}}$ & \\
\hline Modular & $\begin{array}{l}\text { Supplier } s \text { has a relatively high market } \\
\text { share compared to the set of products } \\
\text { ('module') that it supplies to a buyer } b \text {. }\end{array}$ & $+\ln \frac{\sigma_{s}}{\sigma_{b s}}$ & \\
\hline Market & $\begin{array}{l}\text { A low market share for supplier s } \\
\text { relative to the total market share of } \\
\text { product } p \text {. }\end{array}$ & $-\ln \frac{\sigma_{s}}{\sigma_{p}}$ & \\
\hline
\end{tabular}

Notes: The subscripts bspm stand for buyer, supplier, product, and model, respectively. The sum of quantities in the numerators and denominators become market shares after dividing by the quantity for the entire market. In the last four definitions, this normalisation cancels out when dividing the two shares; in the definition of hierarchy, the total market quantity would be a constant in the regression after taking logarithms without affecting the estimates. 
For the other governance types we use a similar approach, but as they are defined over transactions which are actually outsourced and observed in the dataset, it is only a matter of selecting the appropriate relative shares. ${ }^{15}$ We base ourselves on the extensive GVC literature for this. The different market shares that enter these calculations, which are listed in the third column of Table 4, are the total market shares of the buyer, seller, or product over the entire market $\left(\sigma_{b}, \sigma_{s}\right.$ and $\left.\sigma_{p}\right)$, the market share of a particular buyersupplier pair over all products they exchange $\left(\sigma_{b s}\right)$, and the same share limited to a single product $p\left(\sigma_{b s p}\right)$, but still summing over all models. The reasoning why a large value of each dependent variable maps into a high likelihood for a particular governance type is as follows.

Captive relationships will be characterised by a small market share for the supplier relative to the buyer it sells to, i.e., $\sigma_{s} / \sigma_{b}$ is low and the negative of the logarithm of this relative market share - the dependent variable shown in Table 4 - is high (Ahmadjian and Oxley, 2013). ${ }^{16}$ In Relational governance the supplier is independent and sought after for its unique expertise. This expertise is very much at the level of a product which is often uniquely tailored to a buyer's needs (Bensaou, 1999; Pietrobelli and Rabellotti, 2011). As a result, the share of each buyer-product share in the supplier's overall sales is limited (Asanuma, 1989; Sturgeon et al. 2008). The same independence of the supplier is true in Modular relationships, but here one particular product can account for a large share of a supplier's market share (Sturgeon, 2002). The entire business of each buyer will still account for a relative small fraction of a supplier's overall market share, but individual components might dominate a buyer-supplier relationship (Humphrey, 2003). Market relationships will have low supplier market shares relative to the overall product market (Stigler, 1951).

\section{Results}

\subsection{Make-or-buy decision}

The make-or-buy decision is studied extensively in the literature and we already know several features of products or characteristics of transactions that are often linked to outsourcing. To understand better how our three characteristics of interest should be interpreted, we first investigate how they correlate with the initial outsourcing decision. The GVC framework explicitly predicts that high complexity combined with low codifiability and low capability should raise the likelihood of hierarchy.

The regressions reported in the first three columns of Table 5 show that all three theoretical predictions are borne out in the data. Each of the variables has a sign consistent with the GVC prediction in a regression that has the Hierarchy proxy as dependent variable. Firms will choose not to outsource a component and prefer to make the part in-house when the transaction is complex, when it is difficult to codify, and when the capability of the suppliers that produce these parts for competitors is low. The results in column (4) show that the estimates are highly similar when we include all three variables simultaneously in the regression. Even though the complexity and codifiability variables were strongly correlated, they do seem to capture independent variation in the dependent variable.

The first two point estimates are highly statistically significant, but the coefficient on the capability variable is not. There are several reasons for this (also discussed further 
below). First, we only observe the latter variables for firms that we have been able to match to the Amadeus database, which is only half of the sample. Second, by construction, only a few competing firms outsource these parts and hence the characteristics of their suppliers, including their average capability, is likely to be observed with noise. Third, while Hierarchy is a desirable strategy when supplier capabilities are low, this is not the only alternative. The GVC predictions in Table 2 show that Captive outsourcing can be an alternative, at least if codifiability is sufficiently high (relative to the complexity of the transaction).

Table 5 Make-or-buy decision in general

\begin{tabular}{lccccc}
\hline & \multicolumn{5}{c}{ Dependent variable is the hierarchy proxy } \\
\cline { 2 - 6 } & $(1)$ & $(2)$ & $(3)$ & $(4)$ & $(5)$ \\
\hline Complexity & $0.147^{* * *}$ & & & $0.061^{*}$ & -0.004 \\
& $(0.014)$ & & & $(0.034)$ & $(0.036)$ \\
Codifiability & & $-0.178^{* * *}$ & & $-0.156^{* * *}$ & $-0.192^{* * *}$ \\
& & $(0.015)$ & & $(0.037)$ & $(0.039)$ \\
Capability & & -0.017 & -0.022 & $0.112^{* * *}$ \\
& & & $(0.021)$ & $(0.021)$ & $(0.024)$ \\
Control variables & No & No & No & No & Yes \\
Observations & 31,459 & 31,459 & 14,061 & 14,061 & 12,060 \\
R-squared & 0.004 & 0.004 & 0.000 & 0.006 & 0.078 \\
\hline
\end{tabular}

Notes: Estimation is with ordinary least squares in columns (1) to (4) and with the fixed effects panel data estimator in column (5) where a full set of buyer and supplier fixed effects are included. Control variables as described in the data section are included in column (5), but not reported. The statistical significance of the point estimates is indicated as: *for the $10 \%$ level, $* * 5 \%, * * * 1 \%$.

In column (5) of the same table we show estimates where control variables and buyer and supplier fixed effects are also included in the regression. This changes some of the results. Only the codifiability variable still has the expected, negative sign and remains statistically significant. The first-order effect of the complexity variable seems to be captured already by the control variables; the remaining, independent variation is not significantly correlated anymore with the dependent variable.

While the capability variable at least had the expected negative sign in column (4), this is not the case anymore in column (5). Multicollinearity might have contributed to the sign change as the capability of a supplier is now already captured by the value added and capital intensity control variables. However, the coefficient on the capability variable in column (5) is positive and significant, the opposite of our expectation. We have two explanations for this unexpected result. First, this could be due to a measurement problem. We are trying to measure the capability of potential suppliers for parts which are almost always produced in-house. We proxy this using the capability of suppliers in the few cases where such transactions are outsourced, but in these rare occasions the chosen suppliers might simply be unusually capable and not representative. Second, transactions can be outsourced using several forms of supplier governance. In a captive relationship supplier capabilities are predicted to be low. Given that the alternative to 
hierarchy mixes several forms of outsourcing with different predictions on supplier capability, compositional effects can influence the point estimate.

Similarly, an insignificant coefficient on complexity is not evidence against the GVC theory as outsourced transactions will include low complexity Market relationships. We can test the GVC predictions in a more careful way, by constructing a different dependent variable for each pairwise comparison of governance types. In the regressions reported in Table 5, we characterised the governance of transactions along a single dimension, i.e., to what extent are they outsourced or of the Hierarchy type. However, each transaction has a positive probability to be any of the four outsourcing types and we can take into account which type of outsourcing is the most appropriate comparison.

In the next set of regressions, reported in Table 6, we use four different dependent variables, each time measuring the probability of the Hierarchy type relative to the probability for each of the other four types. We can construct the dependent variables in two ways, but the results turned out extremely similar. Either we can take the log difference of two dependent variables listed in Table 4. Alternatively, we construct for each regression a dummy variable which indicates for each transaction which of the two proxies - Hierarchy or the respective outsourcing type - has the highest value (relative to its own median). For example, the dependent variable used in column (1) of Table 6 indicates for each transaction whether it is more likely to be of the hierarchy type or more likely to be Market. In the first case the dummy is coded as one, in the second case as zero.

Table 6 Make-or-buy decisions with specific sourcing (buy) types

\begin{tabular}{lcccc}
\hline & $\begin{array}{c}\text { Hierarchy vs. } \\
\text { market }\end{array}$ & $\begin{array}{c}\text { Hierarchy vs. } \\
\text { captive }\end{array}$ & $\begin{array}{c}\text { Hierarchy vs. } \\
\text { relational }\end{array}$ & $\begin{array}{c}\text { Hierarchyvs. } \\
\text { modular }\end{array}$ \\
\cline { 3 - 5 } & $(1)$ & $(2)$ & $(3)$ & $(4)$ \\
\hline Complexity & $0.330^{* * *}$ & $0.270^{* * *}$ & $-0.316^{* * *}$ & $-0.144^{* *}$ \\
Codifiability & $(0.046)$ & $(0.048)$ & $(0.070)$ & $(0.072)$ \\
& $-0.246^{* *}$ & $-0.116^{* *}$ & 0.094 & $-0.189^{* *}$ \\
Capability & $(0.049)$ & $(0.052)$ & $(0.075)$ & $(0.075)$ \\
& $-0.058^{* *}$ & $0.337^{* * *}$ & $-0.266^{* *}$ & $-0.089^{* *}$ \\
Control variables & $(0.029)$ & $(0.032)$ & $(0.045)$ & $(0.045)$ \\
Observations & Yes & Yes & Yes & Yes \\
R-squared & 6,024 & 7,577 & 3,701 & 3,962 \\
\hline
\end{tabular}

Notes: The dependent variable is a dummy variable that indicates which of the two types listed in the column heading fits best for each transaction. The linear probability model is estimated with ordinary least squares; it includes a full set of buyer and supplier fixed effects and control variables as described in the data section (which are not reported). The statistical significance of the point estimates is indicated as: *for the $10 \%$ level, $* * 5 \%, * * * 1 \%$.

The results in Table 6 use these discrete classifications as dependent variable and the same three explanatory variables as before. A positive coefficient on a variable in column (1) indicates that a high value is positively associated with the hierarchy type and negatively with market outsourcing. To facilitate the interpretation of the results, we have shaded in each column the coefficient that corresponds to the variable where the GVC 
theory predicts a different high or low value for the transaction characteristic for hierarchy than for the relevant outsourcing type. For example, both hierarchy and captive relationships are expected to occur if transactions are complex and supplier capabilities are low. The distinguishing feature is that high codifiability makes captive outsourcing feasible and low codifiability forces the firm to produce the part in-house. Hence we shaded the codifiability coefficient in column (2).

In each of the four columns, the sign we estimate on the shaded coefficients for the variables of interest corresponds to the theoretical predictions in Table 2, even including the control variables, and the coefficients are statistically significant in each of the four cases. The 0.330 estimate in column (1) implies that higher complexity makes outsourcing in a Market relationship particularly unlikely; the -0.116 estimate in column (2) implies that high codifiability facilitates captive relationships, and the -0.266 estimate in column (3) implies that high capability makes outsourcing with a relationship type of governance more likely, all exactly as predicted by the theory.

The variation in sign for the complexity variable across the different regressions in columns (2) to (4) is not necessarily inconsistent with the GVC theory. The complexity of the transaction is not the key distinguishing feature between Hierarchy and the other three relationship types. Nevertheless, the positive estimate of 0.270 in column (2) suggests that captive relationships tend to be more appropriate for less complex transactions than in-house produced parts which is not implausible. In contrast, the regressions distinguishing hierarchy from relational and modular governance generated negative coefficients of -0.316 and -0.144 on the complexity variable. It suggests those governance types are for transactions with even higher complexity than for in-house produced transactions, again not implausible given that these relationships are chosen when suppliers bring unique capabilities.

High codifiability makes outsourcing more likely in three of the four cases. In particular, the -0.116 estimate in column (2) for hierarchy against captive and the -0.189 estimate in column (4) for hierarchy against modular are both negative as predicted by the theory. Market transactions appear even more codifiable (with an estimate of -0.246) and Relational transactions weakly less so (the estimate is 0.094), which is intuitive.

Finally, both relational and modular governance are chosen for transactions where highly capable suppliers are present, as indicated by the -0.266 and -0.089 estimates in columns (3) and (4). When no capable suppliers are available, in-house production is preferred. While the theory predicts that both captive and hierarchy governance are valid alternatives when (potential) supplier capabilities are low, this seems especially the case for the captive type. Market suppliers only need enough capabilities to be able to make non-complex parts, but the estimate of -0.058 suggests that it requires slightly more skills than potential suppliers have when firms choose not to outsource. The estimates on the capability variable are in all four columns exactly in line with the theory and expectations even when control variables are introduced. This contrasts with the unexpected positive estimate of 0.112 in column (5) of Table 5, which highlights the importance of making comparisons with each outsourced type separately.

In sum, predictions of the GVC theory regarding the make-or-buy decision are strongly supported by the estimates. The general decision whether to outsource or not (in Table 5) has no unique predictions if one does not know what type of governance outsourcing will take. While the partial correlations lead to intuitive first-order effects for each explanatory variable on its own, it leads to some counterintuitive estimates when 
control variables are introduced, as outsourcing transactions can be of different types. However, when the choice of governance mode is explicitly taken into account (in Table 6), the estimates on the three key explanatory variables are entirely in line with the predictions.

\subsection{Transitions between governance types}

We treat all transactions in our dataset as a cross-section of observations. While they almost all come from the same decade, they reflect choices on components that are at different stages in the life-cycle of their technologies. Some parts were only introduced recently and are still very novel to the industry. Other parts have matured a lot and many aspects of their design and production have been standardised (Klepper, 1997).

As parts mature, we expect all three explanatory variables of interest to increase, either gradually or in discrete steps. Performance dimensions and other requirements become codifiable if both buyers and suppliers acquire expertise producing parts with a new technology. As they solve problems and gain experience, suppliers acquire capabilities. Eventually, products become standardised and well-understood and they are not considered as complex anymore. Rather than being collaborative sub-assemblies, they gradually become commodified.

We can thus give the choice between alternative governance types an evolutionary interpretation. As we compare how sourcing choices differ between parts with differing codifiability, for example because one part's technology has matured more quickly or for a longer period already, we also learn how the governance choice for a new part is likely to evolve as it matures itself. To present and discuss such possible evolutionary paths in a transparent way, we distinguish between components where codifiability increases first, followed by an evolution where capabilities increase first.

\subsubsection{Technology becomes codified first}

The above evidence suggests that when technologies become codifiable and standardised, the probability of outsourcing increases; in particular, according to the results in Table 6, outsourcing of the captive, modular, or market type. To understand how the relative attractiveness of different sourcing modes evolves without imposing a lot of structure, we show in Table 7 the direct differences of market shares in different situations.

Table 7 Differences in average market shares for components with low or high codifiability

\begin{tabular}{|c|c|c|c|c|}
\hline Codifiability & $\begin{array}{l}\text { Market share of } \\
\text { car models }\end{array}$ & Shares by $O E M$ & $\begin{array}{l}\text { Share by } \\
\text { component }\end{array}$ & $\begin{array}{l}\text { Shares by } \\
\text { suppliers }\end{array}$ \\
\hline \multicolumn{5}{|c|}{ a Full sample } \\
\hline Low & $0.42 \%$ & $1.94 \%$ & $0.43 \%$ & $0.49 \%$ \\
\hline High & $0.42 \%$ & $1.94 \%$ & $0.55 \%$ & $0.37 \%$ \\
\hline \multicolumn{5}{|c|}{ b Only small and young suppliers } \\
\hline Low & $0.39 \%$ & $2.07 \%$ & $0.43 \%$ & $0.56 \%$ \\
\hline High & $0.44 \%$ & $2.24 \%$ & $0.44 \%$ & $0.46 \%$ \\
\hline
\end{tabular}

Comparing the first two rows which distinguish between transactions with low or high codifiability, a notable difference is the low average market share of suppliers when 
transactions are more codifiable, while the components themselves attain a higher average market share, this accords with the TCE logic. As a component is less specific and becomes more standardised, more carmakers will outsource it and competition between suppliers will drives down prices and individual market shares. At the same time, standardisation and outsourcing will increase the share of the component in the overall market for automotive parts. The other two market characteristics, the average share of each model or each OEM (buyer), are comparable across both sets of transactions.

The results in the second panel of Table 7 show that in a subset of the data, namely for small and young suppliers, the share of components is not higher for codifiable transactions but the shares of car models and OEMs are higher. The supplier shares move in the opposite direction, as was the case in the full sample. This evidence is more in line with an alternative theory of the firm, the property rights theory (Grossman and Hart, 1986). It emphasises the relative importance of each firm for joint value creation and is likely to be related to our measure of supplier capability. Once transactions are codifiable and outsourcing becomes more common, a natural further evolution is for suppliers to increase their expertise with the technology and gradually obtain greater power in the relationship. According to the GVC theory predictions in Table 2, we would expect to see the governance to evolve from captive to more modular relationships.

In Table 8 we again use the discrete governance proxies obtained using pairwise comparisons (as in Table 6) to verify whether the different explanatory variables co-move with the governance forms in line with the theoretical predictions. In particular, comparing the predictions for the different governance types in Table 2, we see that there are many instances where two types only differ with respect to one explanatory variable and in those cases we have highlighted the coefficient estimate on the key distinguishing variable.

Table 8 Governance transitions starting from increased codifiability

\begin{tabular}{lccc}
\hline & Hierarchy vs. captive & Captive vs. modular & Modular vs. market \\
\cline { 2 - 4 } & $(1)$ & $(2)$ & $(3)$ \\
\hline Complexity & $0.270^{* * *}$ & $-0.223 * * *$ & $0.308^{* * *}$ \\
Codifiability & $(0.048)$ & $(0.043)$ & $(0.079)$ \\
& $-0.116^{* *}$ & 0.028 & 0.031 \\
Capability & $(0.052)$ & $(0.046)$ & $(0.082)$ \\
& $0.337^{* * *}$ & $-0.295^{* * *}$ & 0.161 \\
Control variables & $(0.032)$ & $(0.028)$ & $(0.155)$ \\
Observations & Yes & Yes & Yes \\
Pseudo R-squared & 7,577 & 9.656 & 5,842 \\
\hline
\end{tabular}

Notes: The dependent variable is a dummy variable that indicates which of the two types listed in the column heading fits best for each transaction. The linear probability model is estimated with ordinary least squares; it includes a full set of buyer and supplier fixed effects and control variables as described in the data section (which are not reported). The statistical significance of the point estimates is indicated as: *for the $10 \%$ level, **5\%, *** $1 \%$. 
If we start from a transaction where complexity is high, but both codifiability and complexity is low, the GVC prediction is that it should optimally occur in-house and the earlier evidence supported this. We can then envision a chain of changes where first the part becomes codifiable, outsourcing increases and suppliers build up capabilities next. After some time, the part becomes entirely standardised and is not considered complex anymore. This chain of events should lead to the following transitions in governance: hierarchy $\rightarrow$ captive $\rightarrow$ modular $\rightarrow$ market.

We already showed that codifiability is indeed positively related with captive outsourcing when compared with Hierarchy and for completeness we repeated that evidence in column (1) of Table 8. The negative coefficient on capability in column (2) indicate that for outsourced transactions, governance is more likely to be modular than captive when supplier capabilities are high as well. Presumably this takes some time as (captive) suppliers first need to acquire expertise. Recall that the positive coefficient on capabilities in column (1) indicates that captive suppliers tend to have low capabilities relative to potential suppliers.

Finally, a transition from modular to market governance is more likely when a transaction is classified as less complex, as evidenced by the positive 0.308 estimate in column (3), again in line with the GVC predictions. The pairwise comparisons of the four governance types in this order, which always differ in one characteristic in Table 2, are supported by point estimates in Table 8 that are always supporting the theory.

\subsubsection{Suppliers acquire capabilities first}

It is possible that suppliers working on related parts or with complementary technologies acquire capabilities to make a particular component even before a transaction becomes codifiable. We now investigate how governance evolves, both in the theory and in the dataset, when capabilities increase before codifiability. The previous evidence suggests it makes outsourcing more likely, see Table 5, and outsourcing of the relational, modular, or market type in particular, see Table 6.

In Table 9 we compare the different market shares directly between transactions where suppliers have low or high capabilities. Comparing between the first two rows indicates that supplier shares are lower when capabilities are higher, but this is now accompanied by a lower component share, the reverse from the pattern in Table 7 . This is what we would expect if outsourcing were of a market type - small firms producing standardised components - but not if important suppliers are producing differentiated products.

In the second panel of Table 9 we show the same share differences limited to transactions that are complex. In this subset of observations, we expect Market relationships not too occur frequently. In line with our intuition, we now see a positive association between supplier shares and capabilities and the negative association between component shares and capabilities disappears as well.

We now consider how the different characteristics predict pairwise differences in governance types if higher capabilities are the trigger to initially convince carmakers to outsource a part. The GVC theory makes specific predictions if first capabilities rise, then codifiability increases and eventually transactions cease to be complex. The corresponding chain of governance should be: hierarchy $\rightarrow$ relational $\rightarrow$ modular $\rightarrow$ market. 
Table 9 Differences in average market shares for suppliers with low or high capability

\begin{tabular}{lcccc}
\hline Capability & $\begin{array}{c}\text { Market share of } \\
\text { car models }\end{array}$ & Shares by OEM & $\begin{array}{c}\text { Share by } \\
\text { component }\end{array}$ & $\begin{array}{c}\text { Shares by } \\
\text { suppliers }\end{array}$ \\
\hline a Full sample & & & & \\
Low & $0.41 \%$ & $2.06 \%$ & $0.43 \%$ & $0.53 \%$ \\
High & $0.42 \%$ & $1.94 \%$ & $0.30 \%$ & $0.45 \%$ \\
b Only complex transactions & & & \\
Low & $0.39 \%$ & $2.02 \%$ & $0.43 \%$ & $0.58 \%$ \\
High & $0.44 \%$ & $2.14 \%$ & $0.41 \%$ & $0.83 \%$ \\
\hline
\end{tabular}

The initial evidence in Table 5 did not provide unambiguous predictions. Higher capabilities were not systematically related to more outsourcing. However, once we distinguished between different forms of supplier governance in Table 6 we found that the insignificant effect was driven by a strong negative association between supplier capabilities and captive relationships, as expected, while the three other sourcing forms were more likely if suppliers are highly capable. The relational form in particular showed a very strong effect, and this is exactly the optimal form predicted by the theory if codifiability remains low and transactions are still complex.

Table 10 Governance transitions starting from increased capabilities

\begin{tabular}{lccc}
\hline & Hierarchy vs. relational & Relational vs. modular & Modular vs. market \\
\cline { 2 - 4 } & $(1)$ & $(2)$ & $(3)$ \\
\hline Complexity & $-0.316^{* * *}$ & $0.242^{* * *}$ & $0.308^{* * *}$ \\
Codifiability & $(0.070)$ & $(0.085)$ & $(0.079)$ \\
& 0.094 & $-0.387^{* * *}$ & 0.031 \\
Capability & $(0.075)$ & $(0.089)$ & $(0.082)$ \\
& $-0.266^{* *}$ & $0.162^{* * *}$ & 0.161 \\
Observations & $(0.045)$ & $(0.053)$ & $(0.155)$ \\
Pseudo R-squared & 7,577 & 2,856 & 5,842 \\
\hline
\end{tabular}

Notes: The dependent variable is a dummy variable that indicates which of the two types listed in the column heading fits best for each transaction. The linear probability model is estimated with ordinary least squares; it includes a full set of buyer and supplier fixed effects and control variables as described in the data section (which are not reported). The statistical significance of the point estimates is indicated as: *for the $10 \%$ level, **5\%,***1\%.

In Table 10 we show how governance evolves further after an initial switch from hierarchy to relational, triggered by an increase in capability - column (1) repeats the earlier evidence from Table 6 . If close collaboration between the supplier and carmakers leads to some standardisation in the technology and ways to more easily communicate performance requirements, it is likely that gradually transactions become more codifiable and other forms of supplier relationships become feasible. In particular, the negative estimate of -0.387 on codifiability in column (2) indicates that Modular governance becomes preferable. However, relational governance remains preferred if the transactions are still highly complex and require especially high capabilities. The final transition from 
modular to market is more likely when complexity finally reduces - as already shown in Table 8.

\section{Conclusions}

We used a novel dataset on sourcing transactions for the auto industry to study whether three characteristics that are popular in the GVC literature are able to accurately predict outsourcing decisions. Once the distinct forms of governance are taken into account, we find the patterns in the data to be remarkably well in line with the theoretical predictions. The correspondence between theory and empirical patterns has three dimensions. First, the observed make-or-buy decisions follow differences in complexity, codifiability, or supplier capability when Hierarchy (in-house) production is compared to specific alternative sourcing modes. Second, when comparing different governance modes of supplier relationships one-by-one, virtually, all correlations with the three transaction characteristics that are the key explanatory variables concord with the theory. Third, if we consider a natural evolution in the three characteristics - i.e., codifiability and supplier capabilities increase, while complexity decreases as a component matures - we can map out a series of governance transitions over time, which depends on the order of the changes.

What do these findings imply for theory? One thing we want to emphasise is that our findings in support of the GVC theory do not imply that we depart from the predictions of alternative theories. In fact, the GVC theory was developed drawing explicitly on other theories and the three determinants of GVC governance play important roles in other theories as well - for instance capability is at the centre of the resource view of the firm, and complexity is closely related to asset specificity in TCE.

A second implication of our analysis is more constructive. An important feature that distinguishes GVC from many other theories is that it breaks open the black box of intermediate, network forms of supplier relationships that are between in-house production and outsourcing to anonymous markets. While the typology of captive, modular, and relational governance is stylised, it is remarkable that even our imperfectly measured transaction characteristics can distinguish between them. In particular, every single coefficient sign in our regressions that compare hierarchy to specific outsourcing types (Table 6) accords with the GVC predictions, even when the regressions contain a rich set of control variables. In contrast, adding control variables to our regressions of Hierarchy versus generic outsourcing [column (5) of Table 5], which lumps the different outsourcing types together lead to unexpected sign reversals on two of the three coefficients. It highlights that failing to distinguish between different governance types makes it much harder to come up with a plausible model for the make-or-buy decision and the theory of the firm.

We consider this only a first step in the investigation of the predictive power of the GVC theory and suggest at least two avenues for future research. One next step would be to test the strength of the GVC predictions out of sample and against specific alternative theories. A second direction is to explicitly identify newly introduced components that use a novel technology and see whether the evolution of its sourcing patterns over time, rather than in the cross-section of transactions, is also in line with the theoretical predictions. 


\section{Acknowledegements}

Financial support from FWO and KU Leuven Program Financing 'Governments and markets' is gratefully acknowledged.

\section{References}

Ahmadjian, C.L. and Oxley J.E. (2013) 'Vertical relationships, hostages, and supplier performance: evidence from the Japanese automotive industry', Journal of Law, Economics, and Organization, Vol. 29, No. 3, pp.485-512.

Antràs, P., Chor, D., Fally, T. and Hillberry, R. (2012) 'Measuring the upstreamness of production and trade flows', American Economic Review: Papers and Proceedings, Vol. 102, No. 3, pp.412-416.

Asanuma, B. (1989) 'Manufacturer-supplier relationships in Japan and the concept of relationspecific skill', Journal of the Japanese and International Economies, Vol. 3, No. 1, pp.1-30.

Baker, G., Gibbons, R. and Murphy, K.J. (2002) 'Relational contracts and the theory of the firm', Quarterly Journal of Economics, Vol. 117, No. 1, pp.39-84.

Bensaou, M. (1999) 'Portfolios of buyer-supplier relationships', Sloan Management Review, Vol. 40, No. 4, pp.35-44.

Brandt, L. and Van Biesebroeck J. (2005) 'Capability building in China's auto supply chains', Chapter 3 in Conference Proceedings: Offshore Outsourcing: Capitalizing on Lessons Learned, Industry Canada and Rotman School of Management.

Gereffi, G. (1999) 'International trade and industrial upgrading in the apparel commodity chain', Journal of International Economics, Vol. 48, No. 1, pp.37-70.

Gereffi, G., Humphrey, J. and Sturgeon, T. (2005) 'The governance of global value chains', Review of International Political Economy, Vol. 12, No. 1, pp.78-104.

Gibbons, R. (2005) 'Four formal(izable) theories of the firm?', Journal of Economic Behavior and Organization, Vol. 58, No. 2, pp.200-245.

Grossman, S.J. and Hart, O.D. (1986) 'The costs and benefits of ownership: a theory of vertical and lateral integration', Journal of Political Economy, Vol. 94, No. 4, pp.691-719.

Haltiwanger, J., Jarmin, R.S. and Miranda, J. (2013) 'Who creates jobs? Small versus large versus young', Review of Economics and Statistics, Vol. 95, No. 2, pp.347-361.

Helper, S. (1991) 'Strategy and irreversibility in supplier relations: the case of the US automobile industry', Business History Review, Vol. 65, No. 4, pp.781-824.

Hofstede, G. (1980) Culture's Consequences: International Differences in Work-Related Values, Sage, New York.

Humphrey, J. (2003) 'Globalization and supply chain networks: the auto industry in Brazil and India', Global Networks, Vol. 3, No. 2, pp.121-141.

Joskow, P. (1985) 'Vertical integration and long-term contracts: the case of coal-burning electric generating plants', Journal of Law, Economics, and Organization, Vol. 1, No. 1, pp.33-80.

Klein, B. (2007) 'The economic lessons of Fisher body-general motors', International Journal of the Economics of Business, Vol. 14, No. 1, pp.1-36.

Klein, B., Crawford, R.G. and Alchian, A.A. (1978) 'Vertical integration, appropriable rents, and the competitive contracting process', Journal of Law and Economics, Vol. 21, No. 2, pp.297-326.

Klepper, S. (1997) 'Industry life cycles', Industrial and Corporate Change, Vol. 6, No. 1, pp. $145-182$. 
Levi, M., Kleindorfer, P.R. and Wu, D.J. (2003) 'Codifiability, relationship-specific information technology investment, and optimal contracting', Journal of Management Information Systems, Vol. 20, No. 2, pp.77-98.

Levin, J. and Tadelis, S. (2010) 'Contracting for government services: theory and evidence from US cities', Journal of Industrial Economics, Vol. 58, No. 3, pp.507-541.

Monteverde, K. and Teece, D. (1982) 'Supplier switching costs and vertical integration in the automobile industry', Bell Journal of Economics, Vol. 13, No. 1, pp.206-213.

Penrose, E. (1959) The Theory of the Growth of the Firm, Basil Blackwell, Oxford.

Pietrobelli, C. and Rabellotti, R. (2011) 'Global value chains meet innovation systems: are there learning opportunities for developing countries?', World Development, Vol. 39, No. 7, pp.1261-1269.

Powell, W. (1990) 'Neither market nor hierarchy: network forms of organization', Research in Organizational Behavior, Vol. 12, pp.295-336.

Schmitt, A. and Van Biesebroeck, J. (2013) 'Proximity strategies in outsourcing relations: the role of geographical, cultural and relational proximity in the European automotive industry', Journal of International Business Studies, Vol. 44, No. 5, pp.475-503.

Sönmez, A. (2013) Multinational Companies, Knowledge and Technology Transfer. Turkey's Automotive Industry in Focus, Springer, Switzerland.

Stigler, G.J. (1951) 'The division of labor is limited by the extent of the market', Journal of Political Economy, Vol. 59, No. 3, pp.185-193.

Sturgeon, T. (2002) 'Modular production networks. A new American model of industrial organization', Industrial and Corporate Change, Vol. 11, No. 3, pp.451-496.

Sturgeon, T., Van Biesebroeck, J. and Gereffi, G. (2008) 'Value chains, networks and clusters: reframing the global automotive industry', Journal of Economic Geography, Vol. 8, No. 3, pp.297-321.

Van Biesebroeck, J. (2003) 'Productivity dynamics with technology choice: an application to automobile assembly', Review of Economic Studies, Vol. 70, No. 1, pp.167-198.

Williamson, O. (1979) 'Transaction-cost economics: the governance of contractual relations', Journal of Law and Economics, Vol. 22, No. 2, pp.233-261.

Williamson, O. (1985) The Economic Institutions of Capitalism: Firms, Markets, Relational Contracting, Macmillan, London.

\section{Notes}

1 The website https://globalvaluechains.org/ lists several hundreds of publications using this framework, most of which are either theoretical contributions or studies of a single industry.

2 The importance of technology and productivity spillovers from MNCs to smaller, local suppliers (Sönmez, 2013) and geographical, cultural, and relational proximity between automakers and suppliers (Schmitt and Van Biesebroeck, 2013) are two related themes that have been studied extensively in the literature.

3 For firms with production plants in multiple industries, we include each as a separate observation.

4 Note that we are not interested in the technical difficulty of producing the product per se. While we expect the contractual complexity and technological complexity to coincide in many cases, we expect an even stronger link with the sophistication of the product's performance characteristics. Product differentiation would be one aspect of this, capturing the importance of performance dimensions that distinguish products beyond price differences.

5 In Table 2 we indicate 'high' for codifiability and capability in the first line, where transactions are not complex. We added an asterisk as these should not be interpreted in an absolute sense, but only relative to the Low complexity of the transaction (in the first column). In particular, it is not at all certain that the requirement of High capabilities for a supplier in 
the Market type is more demanding than the Low capabilities required in captive governance, as only the latter refers to capabilities needed to produce a high(ly) complex transaction.

6 Note that the control variables included in the analysis, in particular the distance between supplier and client plants as well as the full set of client dummies, will hold these effects constant.

7 Brandt and Van Biesebroeck (2005) describe how Western automakers indirectly strengthened their Chinese competitors when they built up the local supply chain in China and were not able to prevent these local suppliers to work for Chinese OEMs. The rush into the most rapidly growing market in the world, exactly at a time when all three US firms were on the verge of bankruptcy, combined with the legal requirement to work through joint ventures, generated a tension between short-run gains and long-run risks. It leads to behaviour that deviated from the expected captive relationships.

8 Klein (2007) investigates the failed attempt of general motors to hold Fisher body a captive supplier.

9 Both of these variables are predicted approximately at the time the supply contract is signed and they are both provided in our dataset.

10 One way to alleviate the uncertainty would be through codification and standards, hence we will predict different governance approaches for complex transactions depending on the codifiability.

11 An even simpler indicator we experimented with classifies components as either stand-alone parts or as sub-assemblies or larger modules that consist of several parts and need to be assembled themselves. Results were qualitatively similar using this alternative measure of complexity.

12 The mean differs from an exact 50-50 split because approximately $10 \%$ of the transactions in the dataset had a number of sub-categories exactly equal to the median value.

13 Further information on the AUTOSAR initiative can be found at http://www.autosar.org/.

14 At the extreme, a component is never outsourced and the variable become infinitely large, but then we would not know anything about it.

15 As we divide two market shares in each definition, the normalisation of the summed quantities in the numerator and denominator always drops out.

16 In some industries, e.g., the apparel industry, supply chains can be buyer-driven leading to captive upstream suppliers, or producer-driven leading to captive downstream retailers (Gereffi, 1999). In the automotive sector only the former type is relevant. 